Check for updates

Cite this: RSC Adv., 2017, 7, 39512

\title{
Influence of polyhedral oligomeric silsesquioxanes (POSS) on the luminescence properties of non- conjugated copolymers based on iridium complex and carbazole units $\dagger$
}

\begin{abstract}
Meijuan Lin, (D)* Caiping Luo, Guang Xing, Longjie Chen and Qidan Ling (DD *
Non-conjugated copolymers with iridium complex and carbazole groups and polyhedral oligomeric silsesquioxane (POSS) moieties as pendant groups were synthesized by free radical copolymerization. The luminescent properties of the polymeric hybrid materials containing the carrier-transporting units (carbazole groups), phosphorescence units (iridium complex) and nano-scale particles (POSS) were studied to explore the effect of POSS on the luminescence of non-conjugated copolymer hybrid materials. The results showed that the copolymers with POSS exhibited good solubility in common organic solvents and better film-formation property. The photoluminescence decays of all copolymers in solid state were bi-exponential indicating the presence of more than one emissive species, which was attributed to intra-polymer chromophore interactions. The luminescence lifetimes of the copolymers were 0.28-1.60 $\mu \mathrm{s}$, indicating phosphorescence emission. The luminescence properties of the copolymers were improved significantly by incorporating bulky POSS into the polymer side-chain, and the maximum quantum efficiency was found to be $52.4 \%$ for ternary copolymer PCz-Ir1.0-POSS6, which was more than six times than that of binary copolymer PCz-Ir1.0 $\left(\Phi_{\mathrm{pl}}=7.7 \%\right)$. The grafted bulky POSS can enhance the thermal stability, however, POSS had no influence on the electrochemical properties of

the copolymers.
\end{abstract}

Received 3rd July 2017

Accepted 4th August 2017

DOI: $10.1039 / c 7 r a 07316$

rsc.li/rsc-advances

\section{Introduction}

Organic-inorganic hybrid materials have played an important role in developing high-performance and functional materials. The hybrid materials are expected to exhibit the advantages of both organic and inorganic materials and may even possess novel characteristics that are not found in the independent organic and inorganic materials. Polyhedral oligomeric silsesquioxane (POSS) is currently receiving much attention due to its well-defined nano-scale organic-inorganic structure, which makes it an ideal building block for constructing nanostructured hybrid materials and nanocomposites. ${ }^{1,2}$ The applications of high-performance POSS nanocomposites can be used as light emitting diodes, ${ }^{3}$ liquid crystals ${ }^{4}$ photoresist materials, ${ }^{5}$ low-dielectric constant materials, ${ }^{6,7}$ luminescent materials, ${ }^{8,9}$ self-assembled block copolymers, ${ }^{10}$ and nanoparticles. ${ }^{11}$

The incorporation of POSS moieties into a polymeric material can dramatically improve its mechanical properties (e.g., strength, modulus, rigidity) as well as reduce its flammability,

Fujian Key Laboratory of Polymer Materials, College of Chemistry and Materials, Fujian Normal University, Fuzhou 350007, China. E-mail: mjlin@fjnu.edu.cn; qdling@fjnu.edu.cn; Tel: +8659183464353

$\dagger$ Electronic supplementary information (ESI) available. See DOI: 10.1039/c7ra07316j heat evolution, and viscosity during processing..$^{12}$ In the aspect of its application in electroluminescent polymers, polymers either side chain tethered ${ }^{13-17}$ or end-capped ${ }^{18}$ by POSS pendent units, as well as fluorescent emitter molecules covalently attached to POSS core, ${ }^{19-22}$ improved the OLED's lifetime, stability, external quantum efficiency (EQE), luminance and color purity, because the thermal stability of the emitter could be improved and the degree of aggregation and excimer formation of the emitter in OLED could be reduced remarkably by chemically incorporating bulky POSS into the conjugated polymer chain. ${ }^{23}$

Phosphorescent iridium complexes give rise to more efficient OLEDs as they can harvest both the singlet and the triplet excitons formed during operation. ${ }^{24}$ However, the iridium complexes used as electroluminescent (EL) materials suffer from self-quenching in the solid state due to the interaction aggregation with their neighboring complexes. To further improve the performance of OLEDs, the iridium complexes anchored POSS macromolecules were developed. ${ }^{25}$ Simultaneous attachment of the host materials and iridium or platinum complex moieties to the POSS core should reduce host-guest phase separation and decreased the interaction among the iridium complexes. The devices based on dualfunctionalized POSS materials with hole-transporting 
(carbazole unit) and heavy-metal complex moieties were showed encouraging efficiency. ${ }^{26-29}$

Compared with the metal complexes, polymers are of great interest as they are more amenable to the solution processing techniques such as spin-coating and ink-jet printing that could be used for low-cost and large-area device fabrication. Phosphorescent polymers with the metal complex covalently attached to the polymer backbone are mainly conjugated polymers such as poly(fluorene), poly(fluorene-carbazole), and poly( $p$-phenylene). ${ }^{24}$ However, the use of conjugated polymers as hosts can be problematic because they can quench triplet excitons from phosphors emitting. Therefore, polymers with a non-conjugated backbone may be suitable for use with phosphorescent emitters. In addition, non-conjugated polymers generally have greater solubility than rigid-rod conjugated polymers, thus facilitating their application to solutionprocessed devices. ${ }^{30}$

In this study, non-conjugated polymers based on iridium complex and carbazole groups and POSS moieties were synthesized by free radical copolymerization. The luminescent properties of polymeric hybrid materials containing simultaneous the carrier-transporting units (carbazole groups), phosphorescence units (iridium complex) and nano-scale particles (POSS) were studied to explore the effect of POSS on the luminescence properties of non-conjugated polymer hybrid materials. The work has not been reported by others so far. The results showed the significantly enhanced luminescence, solubility and stability of the copolymers were attributed to the reduction of aggregation formation because the bulky POSS group prohibited interchain and intrachain interactions.

\section{Experimental section}

\section{General information}

All of the reagents and solvents used in the experiments, except for acrylate carbazole monomer $\mathbf{M}_{1}$, were obtained from commercial suppliers and were used without further purification unless otherwise stated. The acrylate carbazole monomer $\left(\mathrm{M}_{1}\right)$ was synthesized according to a previously reported method. ${ }^{31}$

Thin layer chromatography was performed on G254 silica gel plates from the Qingdao Haiyang Chemical. Column chromatography was performed on Sorbent Technologies brand silica gel (200-300 mesh).

The ${ }^{1} \mathrm{H}$ NMR spectra were recorded on a Bruker AVIII-400 NMR spectrometer (in $\mathrm{CDCl}_{3}$ ). UV-vis absorption spectra were obtained on a Shimadzu UV-2600 spectrophotometer (in $\left.\mathrm{CH}_{2} \mathrm{Cl}_{2}, 1 \times 10^{-5} \mathrm{M}\right)$. The PL spectra were probed on a Shimadzu RF-5301 PC spectrophotometer. The luminescence lifetime and absolute photoluminescence quantum efficiencies in solution and solid state were measured using an Edinburgh Instruments FLS920 Fluorescence Spectrometer. All photographs were recorded on a Canon Powershot G7 digital camera under $365 \mathrm{~nm}$ ultraviolet lamp irradiation. Cyclic voltammetry measurements were carried out on a CHI600D electro-chemical analyzer using a three-electrode configuration under a nitrogen atmosphere. Oxidation potentials were measured by cyclic voltammetry $(\mathrm{CV})$ in acetonitrile with $\mathrm{Ag} / \mathrm{AgCl}$ as a reference electrode. The morphologies of the films were observed by a field-emission scanning electron microscope (FE-SEM JSM7500F) and scanning probe microscope (Bruker Dimension Icon SPM) and thin film samples were prepared by spin-coated of polymer solution $\left(10 \mathrm{mg} \mathrm{mL}^{-1}\right)$ onto ITO-coated glass and dried overnight. Thermal analyses were performed with a Mettler $851 \mathrm{e}$ analysis system under air at a heating rate of $10{ }^{\circ} \mathrm{C}$ $\min ^{-1}$.

\section{Synthesis of the iridium complex monomer $\mathbf{M}_{2}$}

The synthetic routes to the 3-[4-vinylbenzyl]pentane-2,4-dione ligand 1 and the corresponding iridium complex monomer $\mathbf{M}_{2}$ with vinyl diketone ligand, which is the actual unit in the copolymers, are depicted in Scheme 1.

3-[4-Vinylbenzyl]pentane-2,4-dione ligand 1 was constructed by reacting 4-chlorom-ethylstyrene with acetylacetone according to literature procedures. ${ }^{30}$ Yield: $91.4 \%,{ }^{1} \mathrm{H}-\mathrm{NMR}\left(\mathrm{CDCl}_{3}\right.$, $400 \mathrm{MHz}$ ), $\delta: 7.28-7.36(\mathrm{~m}, 2 \mathrm{H}$, phenyl), 6.98-7.12 (m, 2H, phenyl), 6.63-6.70 (m, $1 \mathrm{H}, \mathrm{CH}=), 5.69-5.73\left(\mathrm{~d}, 1 \mathrm{H},=\mathrm{CH}_{2}\right)$, 5.20-5.23 (d, $\left.1 \mathrm{H},=\mathrm{CH}_{2}\right), 3.99\left(\mathrm{t}, 0.43 \mathrm{H},(\mathrm{CO})_{2} \mathrm{CH}-\mathrm{CH}_{2}\right.$ ketoform), 3.64 (s, 1H, phenyl- $\mathrm{CH}_{2} \mathrm{C}$ enol-form), 3.13-3.14 (d, $1 \mathrm{H}$, phenyl- $\mathrm{CH}_{2} \mathrm{C}$ keto-form), 2.07-2.13 (m, 6H, $\mathrm{COCH}_{3}$ ).

Cyclometalated $\operatorname{Ir}(\mathrm{III}) \mu$-chloro-bridged dimer 2 was synthesized according to literature procedures, ${ }^{32,33}$ which involves refluxing $\mathrm{IrCl}_{3} \cdot 3 \mathrm{H}_{2} \mathrm{O}$ with 2-2.5 equiv. of cyclometalating ligand 2-phenylpyridine in a 3:1 mixture of 2-methoxyethanol and water.

The iridium complex monomer $\mathbf{M}_{2}$ were synthesized following literature procedures. ${ }^{24}$ The $\mu$-chloro-bridged dimer 2 $(1.08 \mathrm{~g}, 1.0 \mathrm{mmol})$ was first treated with silver trifluoromethanesulfonate $(0.51 \mathrm{~g}, 2.0 \mathrm{mmol})$ in $30 \mathrm{~mL}$ acetone heated at reflux for $24 \mathrm{~h}$ under argon. The cloudy yellow solution was gravity-filtered before 3-[4-vinylbenzyl]pentane-2,4-dione 1 ( $0.76 \mathrm{~g}, 3.5 \mathrm{mmol}$ ) and $0.53 \mathrm{~g} \mathrm{Na}_{2} \mathrm{CO}_{3}$ were added sequentially. The chelation proceeded very quickly at room temperature. The iridium complex monomer was purified by column chromatography over neutral alumina, followed by precipitation by pouring a dichloromethane solution into hexane to afford iridium complex $\mathrm{M}_{2}$ in a good yield of $71.6 \% .{ }^{1} \mathrm{H}-\mathrm{NMR}\left(\mathrm{CDCl}_{3}, 400 \mathrm{MHz}\right)$, $\delta$ : 8.60-8.61 (d, 2H, phenyl), 7.89-7.91 (d, 2H, phenyl), $7.79(\mathrm{t}, 2 \mathrm{H}$, phenyl), 7.58-7.60 (d, 2H, phenyl), 7.31-7.33 (m, 2H, phenyl), 7.20-7.21 (t, 2H, phenyl), 7.08-7.10 (d, 2H, phenyl), 6.84-6.85 (m, 2H, phenyl), 6.71-6.73 (m, 2H, phenyl), 6.29-6.31 (d, 2H, phenyl), 5.72-5.76 (m, $1 \mathrm{H}, \mathrm{CH}=), 5.37-5.38\left(\mathrm{~d}, 1 \mathrm{H},=\mathrm{CH}_{2}\right), 5.24(\mathrm{~d}, 1 \mathrm{H},=$ $\left.\mathrm{CH}_{2}\right), 3.31-3.73\left(\mathrm{~m}, 2 \mathrm{H}\right.$, phenyl- $\left.\mathrm{CH}_{2} \mathrm{C}\right), 1.82\left(\mathrm{~s}, 6 \mathrm{H}, \mathrm{COCH}_{3}\right)$.

\section{Synthesis of POSS monomer $\mathrm{M}_{3}$}

Synthesis of POSS monomer $\mathrm{M}_{3}$ by corner capping of partially condensed silsesquioxanes $\left[\left(\mathrm{C}_{6} \mathrm{H}_{5}\right)_{7} \mathrm{Si}_{7} \mathrm{O}_{9}(\mathrm{OH})_{3}\right]$ are depicted in Scheme 2 .

Modification of the procedures in the literature ${ }^{34}$ was used. $1.86 \mathrm{~g}(2 \mathrm{mmol})\left(\mathrm{C}_{6} \mathrm{H}_{5}\right)_{7} \mathrm{Si}_{7} \mathrm{O}_{9}(\mathrm{OH})_{3}$ and dry tetrahydrofuran $(40 \mathrm{~mL})$ were added into a flask and the mixture was stirred for 15 min at $-20{ }^{\circ} \mathrm{C}$ under vacuum. Then $\gamma$-(methacryloxy)propyltrimethoxysilane $(0.62 \mathrm{~g}, 2.5 \mathrm{mmol})$ was added dropwise at 

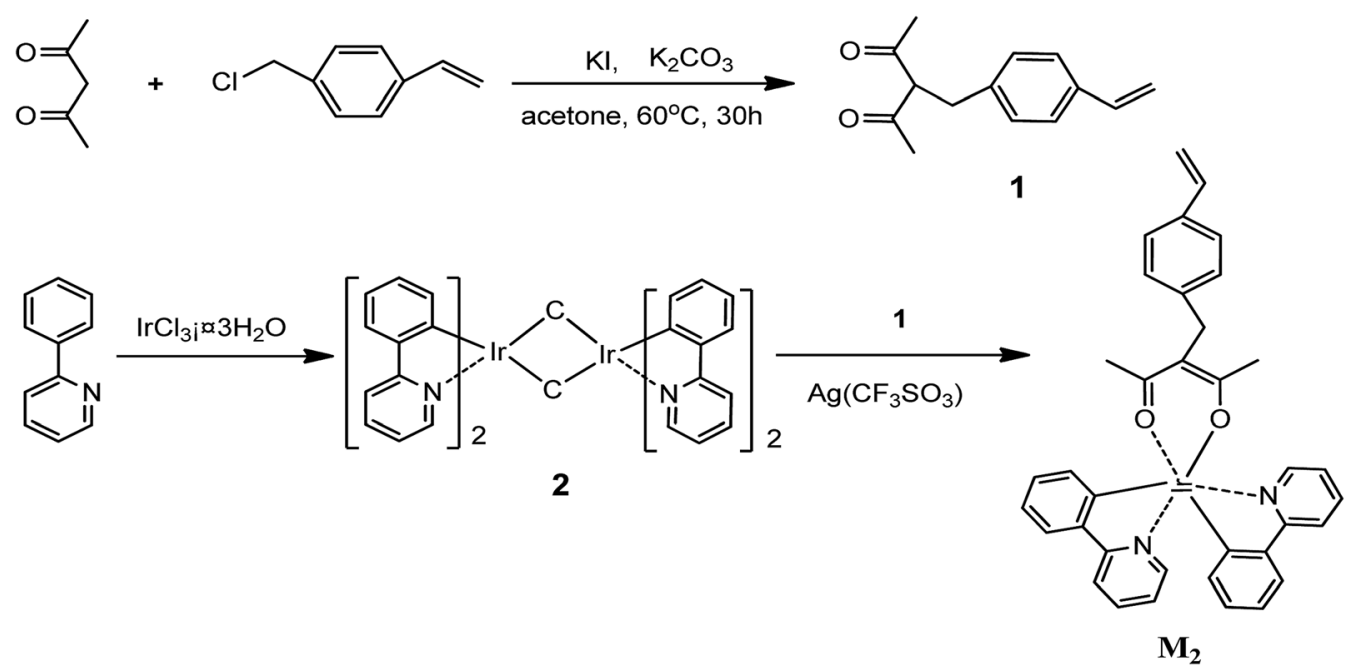

Scheme 1 The synthetic routes of iridium complex monomer $M_{2}$.

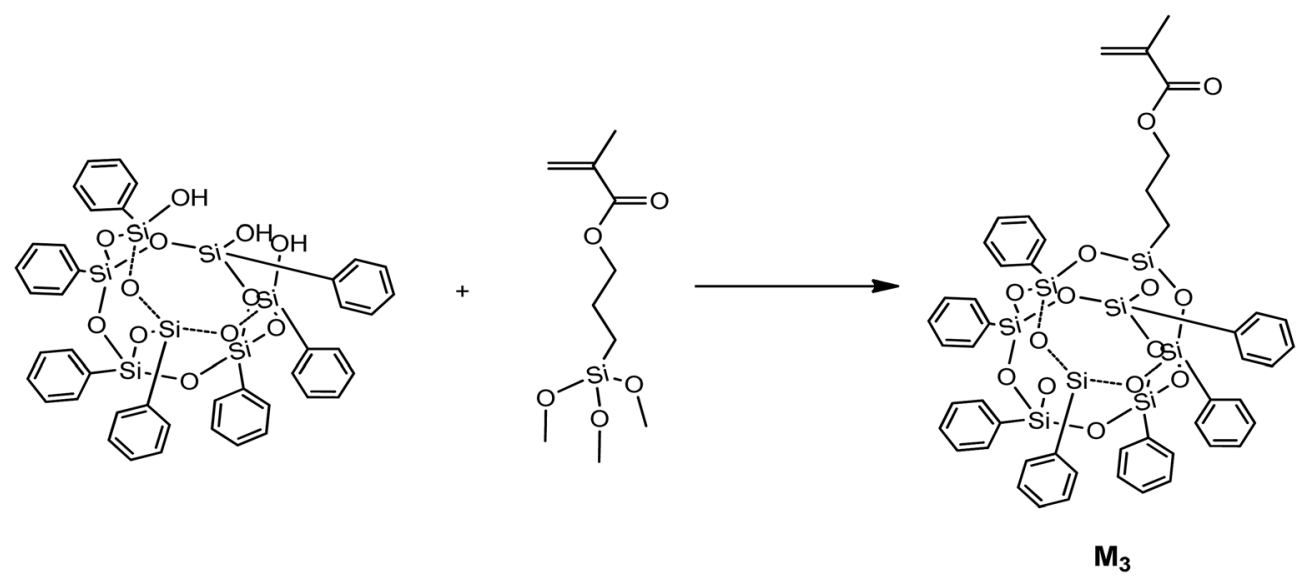

Scheme 2 The synthetic route of the POSS monomer $M_{3}$.

$-20{ }^{\circ} \mathrm{C}$. After the addition, the mixture was warmed to room temperature and stirred for $7 \mathrm{~d}$, and $20 \mathrm{~mL}$ of acetonitrile was added to precipitate the silsesquioxane-containing fraction. The off-white precipitate was collected and dried in vacuo at $50{ }^{\circ} \mathrm{C}$ for $48 \mathrm{~h}$ with a yield of $48.4 \% .{ }^{1} \mathrm{H}-\mathrm{NMR}\left(\mathrm{CDCl}_{3}, 400 \mathrm{MHz}\right), \delta: 7.0-$ 7.92 (m, 35H, phenyl), 6.02-6.08 (d, $1 \mathrm{H},=\mathrm{CH}_{2}$ ), 5.47-5.55 (d, $\left.1 \mathrm{H},=\mathrm{CH}_{2}\right), 4.09\left(\mathrm{~m}, 2 \mathrm{H}, \mathrm{O}-\mathrm{CH}_{2}\right), 1.88-1.93\left(\mathrm{~m}, 3 \mathrm{H},-\mathrm{CH}_{3}\right)$, 1.69-1.76 (m, 2H, -C- $\left.\mathrm{CH}_{2}-\mathrm{C}\right), 0.73-0.88$ (m, 2H, Si- $\left.\mathrm{CH}_{2}\right)$.

\section{Synthesis of the copolymers}

A series of binary copolymers and ternary copolymers were synthesized from carbazole monomer $\mathbf{M}_{1}$, iridium complex monomer $\mathrm{M}_{2}$ and POSS monomer $\mathrm{M}_{3}$ by free radical polymerization using 1 mol\% 1,1-azobis (AIBN) as the initiator according to literature procedures. ${ }^{31}$ The synthetic routes of the copolymers are depicted in Scheme 3.

The polymerizations were carried out at concentrations in the range of $0.35-0.40 \mathrm{M}$ in tetrahydrofuran and the feed ratios of monomers (Table 1). Yield: $60-86 \%$. The solubility of ternary copolymers with POSS is better than that of binary copolymers without POSS. The ternary copolymers exhibit good solubility in common organic solvents such as petroleum ether, acetone, ethyl acetate, chloroform, toluene, THF, DMF and DMSO and can be spin-coated to give good quality neat thin films. The MWs of the copolymers were determined by size exclusion chromatography (SEC) using polystyrene standards and the GPC curves were showed in Fig. S1. $\dagger$ The polydispersity indexes (PDIs) of polymers showed 1.4-2.2.

\section{Results and discussion}

\section{IR spectra analysis}

The IR spectra of the acrylate carbazole monomer $\mathbf{M}_{1}$, iridium complex monomer $\mathrm{M}_{2}$, POSS monomer $\mathrm{M}_{3}$ and binary copolymer PCz-Ir2.5 and ternary copolymer PCz-Ir1.0-POSS6 are shown in Fig. 1. In the IR spectrum of POSS monomer $\mathbf{M}_{3}$, the absorption band at $1130 \mathrm{~cm}^{-1}$ is ascribed to the asymmetric stretching vibration of Si-O-Si. The large peak area suggests that the obtained POSS monomer $\mathrm{M}_{3}$ is mainly composed of $\mathrm{Si}-\mathrm{O}-\mathrm{Si}$ structure. At the same time, the characteristic absorption peaks 


.

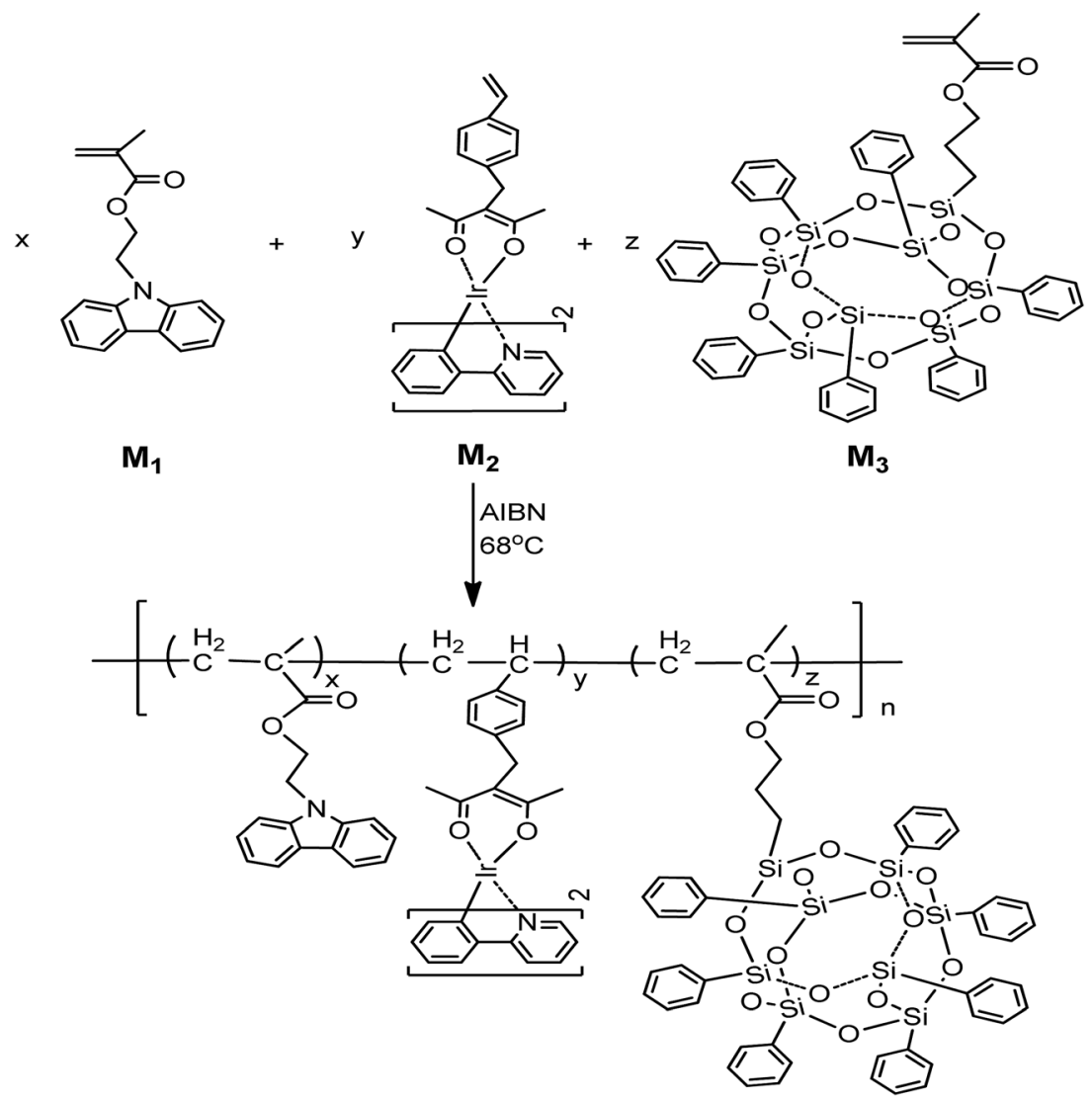

Scheme 3 The synthetic route of the copolymers.

Table 1 Feed mole ratios of monomers and molecular weights and their PDIs of the copolymers

\begin{tabular}{lllll}
\hline & $\begin{array}{l}\text { Feed mole ratio } \\
{\left[M_{1}\right] /\left[M_{2}\right] /\left[M_{3}\right]}\end{array}$ & Yield/\% & Mn $\left(\times 10^{4}\right)$ & PDI \\
\hline PCz-Ir0.5 & $99.5: 0.5$ & 79.2 & 1.0324 & 1.6 \\
PCz-Ir1.0 & $99: 1$ & 64.1 & 0.8146 & 1.5 \\
PCz-Ir2.5 & $97.5: 2.5$ & 85.6 & 0.5110 & 2.1 \\
PCz-Ir5.0 & $95: 5$ & 71.7 & 1.1489 & 1.6 \\
PCz-Ir10 & $90: 10$ & 74.7 & 0.6112 & 2.2 \\
PCz-Ir0.5-POSS2 & $99.5: 0.5: 2$ & 80.1 & 0.7876 & 1.4 \\
PCz-Ir1.0-POSS2 & $99: 1: 2$ & 78.6 & 0.8169 & 2.0 \\
PCz-Ir2.5-POSS2 & $97.5: 2.5: 2$ & 81.7 & 0.5337 & 2.1 \\
PCz-Ir5.0-POSS2 & $95: 5: 2$ & 67.8 & 1.9396 & 1.6 \\
PCz-Ir1.0-POSS4 & $99: 1: 4$ & 60.8 & 0.7979 & 1.8 \\
PCz-Ir1.0-POSS6 & $99: 1: 6$ & 66.0 & 1.3763 & 1.7 \\
PCz-Ir1.0-POSS8 & $99: 1: 8$ & 69.3 & 0.9822 & 2.0
\end{tabular}

of $\mathrm{C}=\mathrm{O}$ at $1718 \mathrm{~cm}^{-1}$ and the $\mathrm{C}=\mathrm{C}$ stretching vibration at 1633 $\mathrm{cm}^{-1}$ indicate that the $\mathrm{C}=\mathrm{C}$ functional group has been introduced. Moreover, the band at $850 \mathrm{~cm}^{-1}$ may be assigned to bending of $\mathrm{Si}-\mathrm{OH}$, was no longer seen in the IR spectrum of POSS monomer, indicating that the cage was completely condensed.

In the IR spectrum of ternary copolymer PCz-Ir1.0-POSS6, the characteristic bands of $\mathrm{Si}-\mathrm{O}-\mathrm{Si}$ stretching band of the cubic cores of POSS at $1135 \mathrm{~cm}^{-1}$, the deformation vibration of POSS skeletal at $495 \mathrm{~cm}^{-1}$ and the band at $699 \mathrm{~cm}^{-1}$ of the $\mathrm{Si}-\mathrm{C}$ stretching vibration ${ }^{35}$ indicate that the POSS moiety is incorporated into polymer. FT-IR curves of the copolymers (PCzIr2.5 and PCz-Ir1.0-POSS6) and carbazole monomer $\mathbf{M}_{1}$ are nearly the same due to the large amounts of carbazole added and the overlap of the peaks. Compared with the spectrum of the carbazole monomer $\mathrm{M}_{1}$, the stretching vibration peak of carbazole $\mathrm{C}-\mathrm{N}$ shifts to $1151 \mathrm{~cm}^{-1}$ and the strong characteristic absorption peak at $1720 \mathrm{~cm}^{-1}$ of $\mathrm{C}=\mathrm{O}$ has a blue-shifted to $1730 \mathrm{~cm}^{-1}$ for the copolymers. Moreover, the characteristic

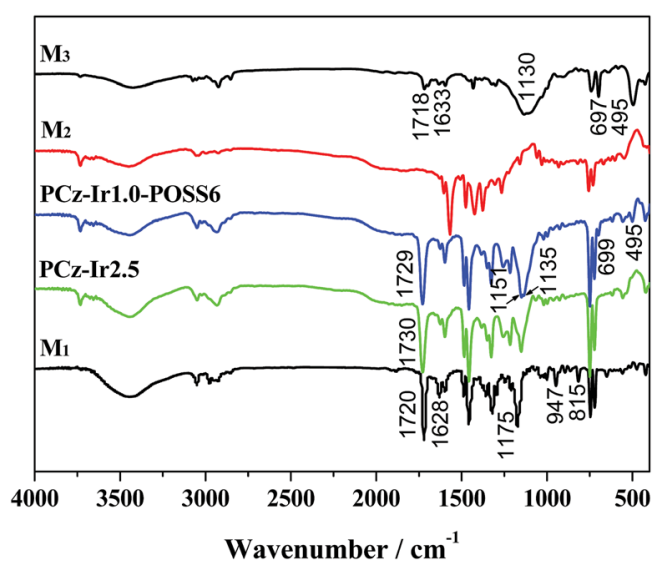

Fig. 1 IR spectra of monomers $M_{1}, M_{2}, M_{3}$ and copolymers PCz-Ir2.5, PCz-Ir1.0-POSS6. 
bands of the $\mathrm{C}=\mathrm{C}$ out-of-plane rocking vibration at $947 \mathrm{~cm}^{-1}$ and $815 \mathrm{~cm}^{-1}$ and the peak at $1628 \mathrm{~cm}^{-1}$ assigned to $\mathrm{C}=\mathrm{C}$ stretching vibration ${ }^{36}$ were not present, indicating that the polymerization reaction was complete. The copolymers did not appeared characteristic absorption bands of iridium complex $\mathbf{M}_{2}$ due to its lower concentration.

\section{UV-vis absorption spectra analysis}

The UV-vis absorption spectra of the acrylate carbazole monomer $\mathbf{M}_{1}$, iridium complex monomer $\mathbf{M}_{2}$, and copolymers PCz-Ir1.0, PCz-Ir1.0-POSS2, PCz-Ir1.0-POSS6 in dichloromethane solution $\left(1 \times 10^{-5} \mathrm{~mol} \mathrm{~L}^{-1}\right)$ are shown in Fig. 2. The iridium complex $\mathrm{M}_{2}$ shows intense absorption from ligand $\pi-\pi^{*}$ and weak absorption from MLCT transitions. The dominant absorption bands in the range of 220-350 $\mathrm{nm}$ are assigned to spin-allowed ligand-centred (LC) ${ }^{1} \pi-\pi^{*}$ transitions of cyclometalated ligand. Both ${ }^{1}$ MLCT (spin-allowed metal-to-ligand charge transfer) and ${ }^{3}$ MLCT (spinforbidden) bands are typically observed for the complex. The high degree of spin-orbit coupling is evident in comparing the oscillator strengths for the two MLCT bands. The singlet and triplet MLCT bands fall at 405 and $460 \mathrm{~nm}$, respectively. ${ }^{37}$

In the UV-vis spectrum of $\mathbf{M}_{1}$, the absorption peaks at $237 \mathrm{~nm}$ and $294 \mathrm{~nm}$ are attributed to the characterized absorption bands of E2 and B of carbazole group and peak at $261 \mathrm{~nm}$ is ascribed to $\mathrm{n}-\pi^{*}$ transition of carbonyl.

UV-vis spectra curves of the copolymers PCz-Ir1.0, PCz-Ir1.0POSS2, PCz-Ir1.0-POSS6 are almost the same as that of the acrylate carbazole $\mathrm{M}_{1}$. The peaks at $237 \mathrm{~nm}, 261 \mathrm{~nm}, 294 \mathrm{~nm}$, $328 \mathrm{~nm}$ and $342 \mathrm{~nm}$, which come from the carbazole segment, dominate UV-vis absorption of the copolymers. However, the absorption strength of the copolymers is higher than that of the acrylate carbazole $\mathbf{M}_{1}$. Meanwhile, the absorption peak of iridium complex in copolymers is covered with carbazole absorption peak due to iridium complex low concentration.

\section{Photoluminescence spectra analysis}

Fig. 3 shows the photoluminescence spectra of the acrylate carbazole $\mathbf{M}_{1}$, iridium complex $\mathbf{M}_{2}$, binary copolymers and ternary copolymers with $2 \mathrm{~mol} \%$ POSS in $\mathrm{CH}_{2} \mathrm{Cl}_{2}$ solution at room temperature (a) and the photographs of the copolymers

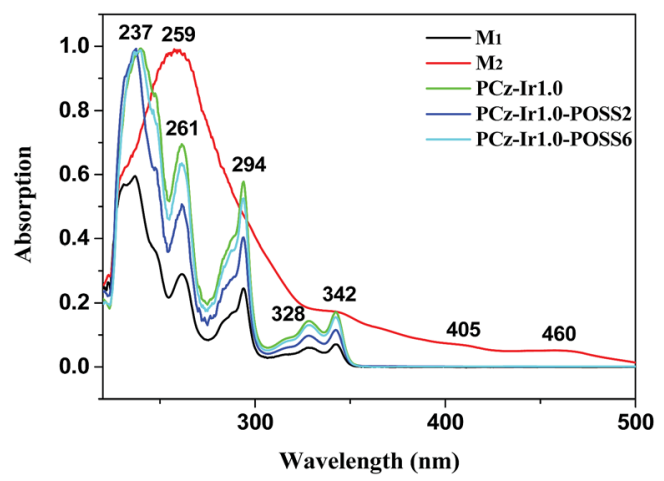

Fig. 2 UV-vis absorption spectra of monomers $M_{1}, M_{2}$ and the copolymers PCz-Ir1.0, PCz-Ir1.0-POSS2, PCz-Ir1.0-POSS6 in $\mathrm{CH}_{2} \mathrm{Cl}_{2}$.

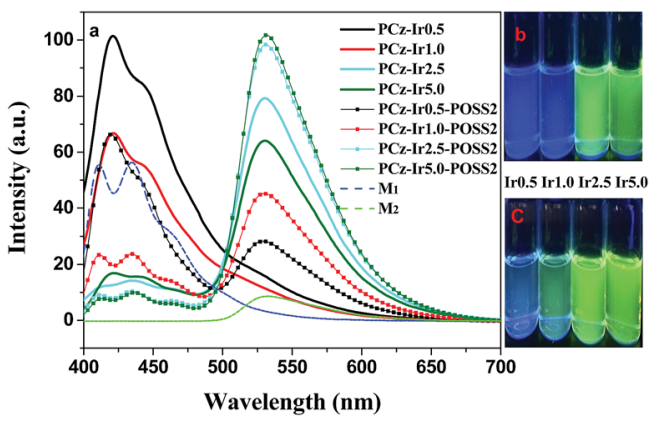

Fig. $3 \mathrm{PL}$ spectra of the acrylate carbazole $M_{1}$, iridium complex $M_{2}$ and the copolymers in $\mathrm{CH}_{2} \mathrm{Cl}_{2}$ (a), photographs of the copolymers without POSS (b) and with 2 mol\% POSS (c) in $\mathrm{CH}_{2} \mathrm{Cl}_{2}$ solution under $365 \mathrm{~nm}$ ultraviolet lamp irradiation.

without POSS (b) and with 2 mol\% POSS (c) in $\mathrm{CH}_{2} \mathrm{Cl}_{2}$ solution under $365 \mathrm{~nm}$ ultraviolet lamp irradiation. As shown in Fig. 3a, all of copolymers in $\mathrm{CH}_{2} \mathrm{Cl}_{2}$ solution exhibit dual emissions of blue and green emission bands, in which the blue emission bands at around 420 and $435 \mathrm{~nm}$ are attributed to the host carbazole units $\mathbf{M}_{1}$ and the green emission band at around $530 \mathrm{~nm}$ is assigned to the guest iridium complex units $\mathbf{M}_{2}$. With the increase of iridium complex content from 0.5 to $5.0 \mathrm{~mol} \%$, the green emission increases, while the blue emission becomes weak (Fig. 3). It is suggested that the iridium complex unit has been incorporated into the polymer backbone and there is energy transfer from the host (donor) carbazole units to guest (acceptor) iridium complex units. The transfer's degree is connected with content of the iridium complex and the POSS unit. The green emission becomes stronger with the increase of iridium complex content in the binary and ternary copolymers, which indicates that more charges are trapped on the iridium complex owing to its higher content.

Compared with binary copolymers, the energy transfer in the ternary copolymers is more efficient even for iridium complex content as low as $0.5 \mathrm{~mol} \%$ and the intensity of the green emission is higher at same mole ratio of carbazole units and iridium complex units, which indicates that incorporated of the POSS into the polymer backbone can promote the energy transfer between donor and acceptor. However, the incorporation of the POSS does not affect the emission wavelength.

When the content of iridium complex is as high as $5.0 \mathrm{~mol} \%$, the green emission of ternary copolymer PCz-Ir5.0-POSS2 is still much strong than that of binary copolymer PCz-Ir5.0, which indicates that the introduction of POSS units into the polymer can efficiently separate or dilute phosphorescent emission groups and effectively inhibit the aggregation of the iridium complexes, thus concentration quenching phenomenon is restrained further in solution.

The PL spectra and luminescent photographs of binary copolymers and ternary copolymers with 2 mol\% POSS in solid powder are shown in Fig. 4. Compared with copolymers in solution (Fig. 3a), the luminescence spectra of the copolymers in solid state are some different from in solution. The results show that the emissions are dominated by a green peak at around $557 \mathrm{~nm}$ responsible for iridium complex emission. It is 

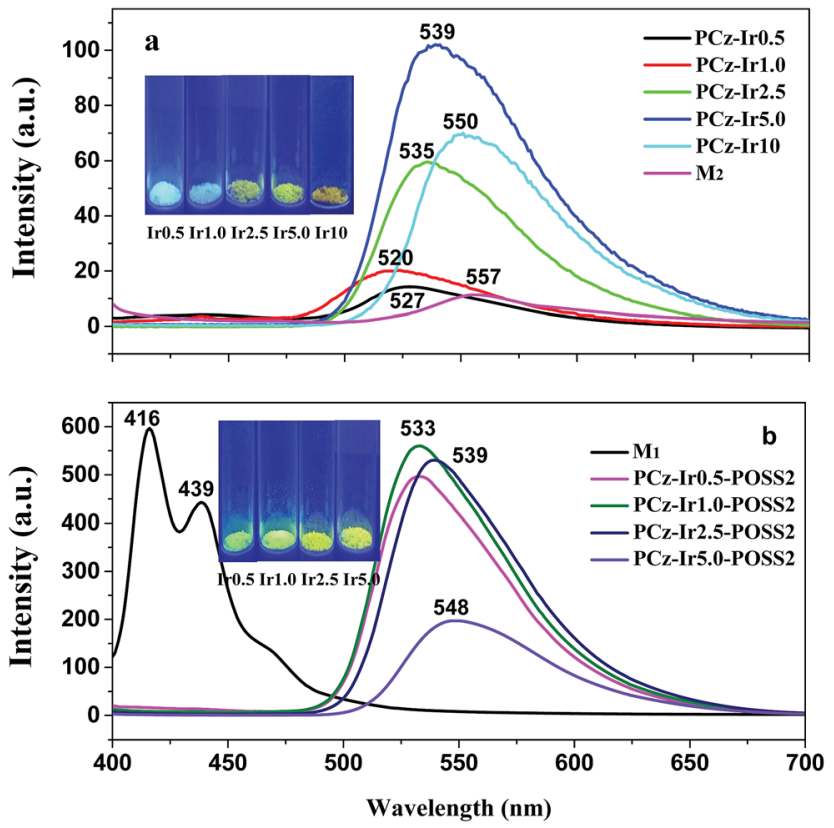

Fig. 4 The PL spectra of binary copolymers (a) and ternary copolymers (b) in solid state (inset: luminescent photographs of the copolymers with different iridium complex content under $365 \mathrm{~nm}$ ultraviolet lamp irradiation).

suggested that the energy transfer from the host carbazole segment to the iridium complex in solid states is more efficient, compared with the polymers in $\mathrm{CH}_{2} \mathrm{Cl}_{2}$ solution. Energy transfer is proportional to the molecular distance of the luminescence materials involved. The distance between the host units and the guest units is relatively fixed by covalent bond, and thus, intramolecular energy transfer effects can still be seen even in dilute concentrations (Fig. 3a). However, no blue emission or weak blue emission from host is seen due to stronger intramolecular and intermolecular energy transfer in the solid state as molecules are piled up and the distance between guest-host systems is smaller. ${ }^{20}$

As shown in Fig. 4, with the increase of the iridium complex content in the copolymers, the intensity of green emission increases at first and then decreases, and emission peaks are slightly red-shifted from $527 \mathrm{~nm}$ for PCZ-Ir0.5 to $550 \mathrm{~nm}$ for PCz-Ir10 (Fig. 4a), and from $532 \mathrm{~nm}$ for PCZ-Ir0.5-POSS2.0 to 548 nm for PCZ-Ir5.0-POSS2.0 (Fig. 4b), respectively. Compared to binary copolymers, the energy transfer in the ternary copolymers in the solid state is more efficient even for iridium complex content as low as $0.5 \mathrm{~mol} \%$ and the intensity of the green emission is much higher at same mole ratio of carbazole units and iridium complex units, just as in solution.

To study the effect of the POSS content on the luminescent property of the polymers, the PL spectra and luminescent photographs of the copolymers with different content of POSS both in solution and in solid state were measured. As shown in Fig. 5, along with an increase in POSS content from 0 to $6 \mathrm{~mol} \%$, the green emission increases both in solution and in solid. When the content of POSS is $6 \mathrm{~mol} \%$, the green intensity of ternary copolymer PCz-Ir1.0-POSS6 is the highest among all copolymers.

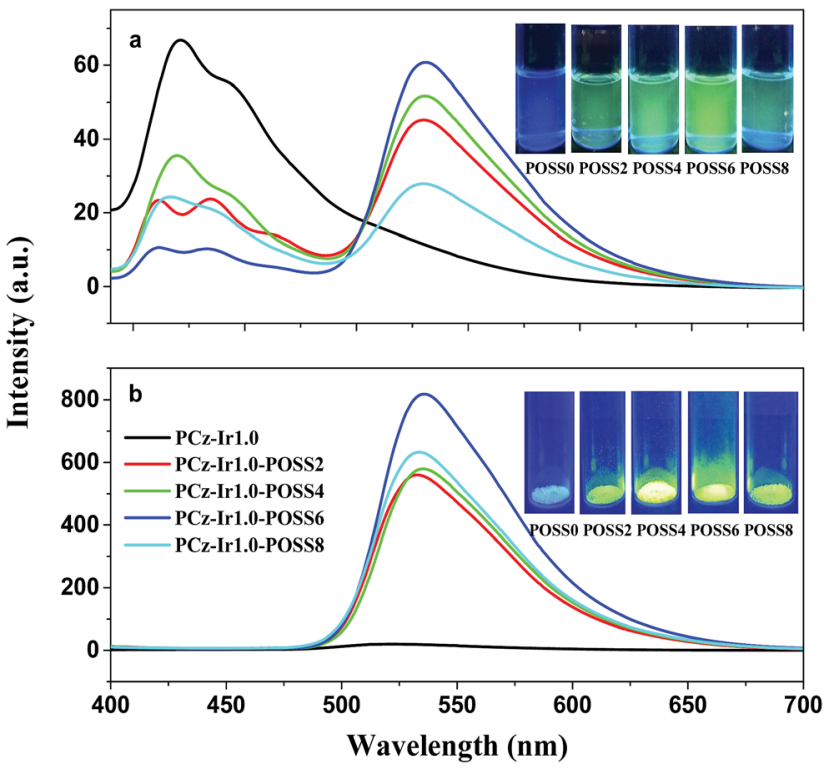

Fig. 5 The PL spectra of copolymers with different content of POSS in $\mathrm{CH}_{2} \mathrm{Cl}_{2}$ solution (a) and in solid state (b) (inset: luminescent photographs of the copolymers under $365 \mathrm{~nm}$ ultraviolet lamp irradiation).

While the content of POSS is $8 \mathrm{~mol} \%$, the green intensity decreases somewhat, which may result from the block of POSS that may lead to incomplete energy transfer between host and guest in intramolecular and intermolecular due to higher density of POSS groups. The photophysical data of the monomers $\mathbf{M}_{1}, \mathbf{M}_{2}$ and the copolymers are summarized in Table 2.

In order to further explore the extents of energy transfer between the host $\mathrm{PCz}$ (donor) and guest iridium complex (acceptor), the time-resolved fluorescence decay times of the donor were measured from the decay curves of emission at $435 \mathrm{~nm}$ from the $\mathrm{PCz}$ donor in $10^{-5} \mathrm{M} \mathrm{CH}_{2} \mathrm{Cl}_{2}$ solution (Table 3, Fig. $\mathrm{S} 2 \dagger)$. As shown in Table 3, the lifetime of $\mathrm{PCz}$ is $4.01 \mathrm{~ns}$ and there are a downtrend in the excited-state lifetime of the donor with increased acceptor concentrations and the lifetimes of the ternary copolymers PCz-Ir0.5-POSS2 (2.92 ns), PCz-Ir1.0-POSS2 (2.0 ns) are shorter than those of the binary copolymers $\mathrm{PCz}$ Ir0.5 (3.92 ns), PCz-Ir1.0 (3.41 ns). The energy transfer efficiency $\left(E_{\mathrm{t}}\right)$ can be calculated using the formula: ${ }^{38} E_{\mathrm{t}}=1-\tau / \tau_{0}$, where $\tau_{0}$ and $\tau$ are the lifetime of the donor $(\mathrm{PCz})$ in the absence and presence of the acceptor (iridium complex), respectively. When the content of the guest iridium complex increases from $0.5 \%$ to $1.0 \%$, the $E_{\mathrm{t}}$ value is enhanced from $2.2 \%$ to $15.0 \%$ for binary copolymers and from $27.2 \%$ to $50.1 \%$ for ternary copolymers, respectively. This illustrates that there is a more efficient energy transfer from the $\mathrm{PCz}$ host to the guest in ternary copolymers than in binary copolymers.

\section{Quantum efficiency}

Quantum efficiency $\left(\Phi_{\mathrm{pl}}\right)$ measurements were carried out at 293 $\mathrm{K}$ in an integrating sphere and were taken as the average of three separate determinations and were reproducible within $10 \%$. The phosphorescent quantum efficiencies for iridium 
Table 2 The photophysical data of the monomers $M_{1}, M_{2}$ and copolymers

\begin{tabular}{lllll}
\hline Compound & $\lambda_{\mathrm{abs}}{ }^{a},($ solution$),(\mathrm{nm})$ & $\lambda_{\mathrm{em}}{ }^{b},($ solution$),(\mathrm{nm})$ & $\lambda_{\mathrm{em}}{ }^{c}$, (powder), (nm) & $\Phi_{\mathrm{pl}}{ }^{d},(\mathrm{powder}),(\%)$ \\
\hline $\mathrm{M}_{1}$ & $231,237,261,294,328,343$ & 411,434 & 416,439 & - \\
$\mathrm{M}_{2}$ & $232,259,343,462$ & 530 & 557 & 7.8 \\
PCz-Ir0.5 & $239,261,293,328,342$ & $421(\mathrm{~s}), 443,520$ & 527 & 7.7 \\
PCz-Ir1.0 & $240,261,294,328,342$ & $421(\mathrm{~s}), 443,520$ & 520 & 15.1 \\
PCz-Ir2.5 & $241,261,293,328,342$ & $411,436,530(\mathrm{~s})$ & 535 & 24.2 \\
PCz-Ir5.0 & $238,261,293,328,343$ & $421,444,530(\mathrm{~s})$ & 539 & 19.2 \\
PCz-Ir10 & $237,261,292,329,342$ & $530(\mathrm{~s})$ & 550 & 26.0 \\
PCz-Ir0.5-POSS2 & $238,261,293,328,342$ & $419(\mathrm{~s}), 444,529$ & 532 & 39.6 \\
PCz-Ir1.0-POSS2 & $237,261,294,328,342$ & $411,434,530$ & 533 & 26.5 \\
PCz-Ir2.5-POSS2 & $237,261,294,328,342$ & $410,433,530(\mathrm{~s})$ & 539 & 5.5 \\
PCz-Ir5.0-POSS2 & $238,261,295,328,342$ & $412,436,531$ & 548 & 43.8 \\
PCz-Ir1.0-POSS4 & $236,261,294,327,342$ & $419,446,529$ & 535 & 52.4 \\
PCz-Ir1.0-POSS6 & $238,261,294,328,343$ & $410,433,530(\mathrm{~s})$ & 536 & 533 \\
PCz-Ir1.0-POSS8 & $237,261,295,328,342$ & $415,435,530$ &
\end{tabular}

${ }^{a}$ Measured in $\mathrm{CH}_{2} \mathrm{Cl}_{2}$ at a concentration of $10^{-5} \mathrm{M}$ at $298 \mathrm{~K} .{ }^{b}$ Recorded in $\mathrm{CH}_{2} \mathrm{Cl}_{2}$ at a concentration of $10^{-5} \mathrm{M}$ at $298 \mathrm{~K}$ at $375 \mathrm{~nm}$ excitation wavelength. ${ }^{c}$ Measured in powder at $375 \mathrm{~nm}$ excitation wavelength. ${ }^{d} \Phi_{\mathrm{pl}}$ in powder were measured in an integrating sphere at $293 \mathrm{~K}$.

Table 3 Time-resolved fluorescence decay times and energy transfer efficiency $\left(E_{t}\right)$ of the donor

\begin{tabular}{lllcll}
\hline Copolymer & PCz & PCz-Ir0.5 & PCz-Ir1.0 & $\begin{array}{l}\text { PCz-Ir0.5- } \\
\text { POSS2 }\end{array}$ & $\begin{array}{l}\text { PCz-Ir1.0- } \\
\text { POSS2 }\end{array}$ \\
\hline$\tau^{a}(\mathrm{~ns})$ & 4.01 & 3.92 & 3.41 & 2.92 & 2.00 \\
$E_{\mathrm{t}}{ }^{b}(\%)$ & - & 2.2 & 15.0 & 27.2 & 50.1
\end{tabular}

${ }^{a}$ Recorded in $\mathrm{CH}_{2} \mathrm{Cl}_{2}$ at a concentration of $10^{-5} \mathrm{M}$ at $293 \mathrm{~K}$ at $\lambda_{\text {ex }}=$ $375 \mathrm{~nm}$ and $\lambda_{\mathrm{em}}=435 \mathrm{~nm} .{ }^{b} E_{\mathrm{t}}=1-\tau / \tau_{0}$.

complex and copolymers in powder are listed in Table 2. The results show that the quantum efficiencies of the copolymers are higher than that of iridium complex $\left(\Phi_{\mathrm{pl}}=3.8 \%\right)$, and quantum efficiencies of the ternary copolymers $\left(\Phi_{\mathrm{pl}}=24.5-\right.$ $52.4 \%)$ are higher than those of the binary copolymers $\left(\Phi_{\mathrm{pl}}=\right.$ 7.0-24.2\%). With the increase of the iridium complex content, $\Phi_{\mathrm{pl}}$ of copolymer increases at first and then decreases, just as luminescent intensity. For the binary polymer, the maximum $\Phi_{\mathrm{pl}}$ is found to be $24.2 \%$ for PCz-Ir5.0. The $\Phi_{\mathrm{pl}}$ of the ternary copolymers improves significantly by introduction of POSS, and the maximum $\Phi_{\mathrm{pl}}$ is found to be $52.4 \%$ for PCz-Ir1.0-POSS6, which is more than six times than that of binary copolymer PCz-Ir1.0 $\left(\Phi_{\mathrm{pl}}=7.7 \%\right)$.

It is noteworthy that more iridium complex is needed to enhance luminescence for the binary copolymer, however, the $\Phi_{\mathrm{pl}}$ of the ternary copolymer is higher even for iridium complex content as low as $0.5 \mathrm{~mol} \%$, thus less iridium complex can reduce the cost and avoid "Roll down" phenomenon duo to high content iridium complex.

\section{Phosphorescence decay}

The time-resolved phosphorescence decay profiles of the copolymers were measured in powder at $293 \mathrm{~K}$ and phosphorescence decay followed the bi-exponential equation: $F(t)=B_{1^{-}}$ $\exp \left(-t / \tau_{1}\right)+B_{2} \exp \left(-t / \tau_{2}\right)$, where $\tau_{1}$ and $\tau_{2}$ are the short and the long decay components, respectively, and parameters $B_{1}$ and $B_{2}$ are the fitting constants, indicating the presence of more than one emissive species, which was attributed to intra-polymer

Table 4 Luminescence lifetimes and decay parameters of the copolymers

\begin{tabular}{|c|c|c|c|c|c|c|c|}
\hline Copolymer & $\lambda_{\mathrm{em}},(\mathrm{nm})$ & $\tau_{1},(\mathrm{~ns})$ & $\tau_{2},(\mathrm{~ns})$ & $\chi^{2}$ & $B_{1},(\%)$ & $B_{2},(\%)$ & $\tau_{0}^{a},(\mu s)$ \\
\hline PCz-Ir0.5 & 527 & 731.51 & 1612.08 & 1.179 & 18.17 & 81.83 & 1.45 \\
\hline PCz-Ir1.0 & 520 & 185.78 & 1201.72 & 1.095 & 7.72 & 92.28 & 1.12 \\
\hline PCz-Ir2.5 & 535 & 455.59 & 1160.72 & 1.204 & 20.23 & 79.77 & 1.02 \\
\hline PCz-Ir5.0 & 539 & 197.44 & 717.15 & 1.079 & 24.17 & 75.83 & 0.59 \\
\hline PCz-Ir10 & 550 & 126.99 & 409.68 & 0.993 & 44.97 & 55.03 & 0.28 \\
\hline PCz-Ir0.5-POSS2 & 532 & 676.54 & 1707.71 & 1.022 & 16.21 & 83.79 & 1.54 \\
\hline PCz-Ir1.0-POSS2 & 533 & 591.23 & 1366.72 & 1.058 & 15.53 & 84.47 & 1.25 \\
\hline PCz-Ir2.5-POSS2 & 539 & 590.73 & 1366.37 & 1.057 & 15.50 & 84.50 & 1.25 \\
\hline PCz-Ir5.0-POSS2 & 548 & 233.58 & 766.06 & 1.133 & 21.09 & 78.91 & 0.65 \\
\hline PCz-Ir1.0-POSS4 & 535 & 638.60 & 1772.90 & 1.077 & 15.07 & 84.93 & 1.60 \\
\hline PCz-Ir1.0-POSS6 & 536 & 649.23 & 1502.94 & 1.095 & 19.65 & 80.35 & 1.34 \\
\hline PCz-Ir1.0-POSS8 & 533 & 654.76 & 1486.87 & 1.230 & 20.98 & 79.02 & 1.31 \\
\hline
\end{tabular}

${ }^{a} \tau_{0}=\sum \tau_{i} \times B_{i} \%$. 


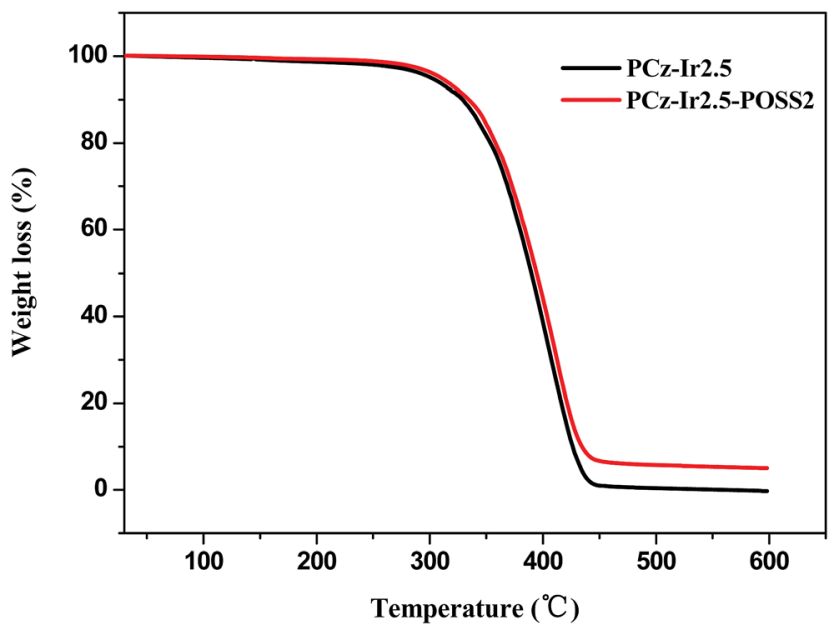

Fig. 6 TG curves of the copolymers PCz-Ir2.5 and PCz-Ir2.5-POSS2.

chromophore interactions. ${ }^{24}$ The luminescence lifetimes of the copolymers have been determined from the decay curves (Fig. S3†) and resulting lifetimes are given in Table 4.

As shown Table 4, it shows that the phosphorescence lifetimes are $0.28-1.60 \mu \mathrm{s}$, which is shorter than that of popular fac-[Ir(ppy $\left.)_{3}\right](\mathrm{ca} .4 .75 \mu \mathrm{s})$. As we all know, the long life-time would increase the possibility of intrinsic triplet-triplet annihilation in the phosphorescent OLEDs. Therefore, the short phosphorescent lifetimes of these copolymers could effectively restrain the phosphorescence self-quenching to show high quantum yield. Meantime, excited-state lifetimes are in the microsecond regime for all copolymers, which it clearly suggests that the emitting state has triplet character, indicating phosphorescence emission. With the increase of iridium complex content, the phosphorescent lifetimes of these copolymers show the tendency of decrease. The influence of the POSS content on phosphorescent lifetime is not obvious.

\section{Electrochemical properties}

Electrochemical properties of the copolymers including the HOMO and LUMO energy levels were investigated to characterize and compare the electronic properties of the copolymers through cyclic voltammetry (CV) measurements. All copolymers showed similar CV curves (Fig. S4 $\dagger$ ) and exhibited similar reversible oxidation processes, which could be assigned to the oxidation of electron-donating carbazole moiety, with the onset potentials ( $E_{\text {onset }}^{\text {ox }}$ ) of $0.84-1.08 \mathrm{~V}$. Compared with the ionization potential of ferrocene at $-4.8 \mathrm{eV}$, the HOMO level of the copolymers could be calculated to be $5.64-5.88 \mathrm{eV}$. In addition, the LUMO levels of the copolymers were estimated to be 2.33$2.58 \mathrm{eV}$ from their absorption edge. All results were listed in Table S1. $\uparrow$ The HOMO levels, the LUMO levels and the $E_{g}$ of the
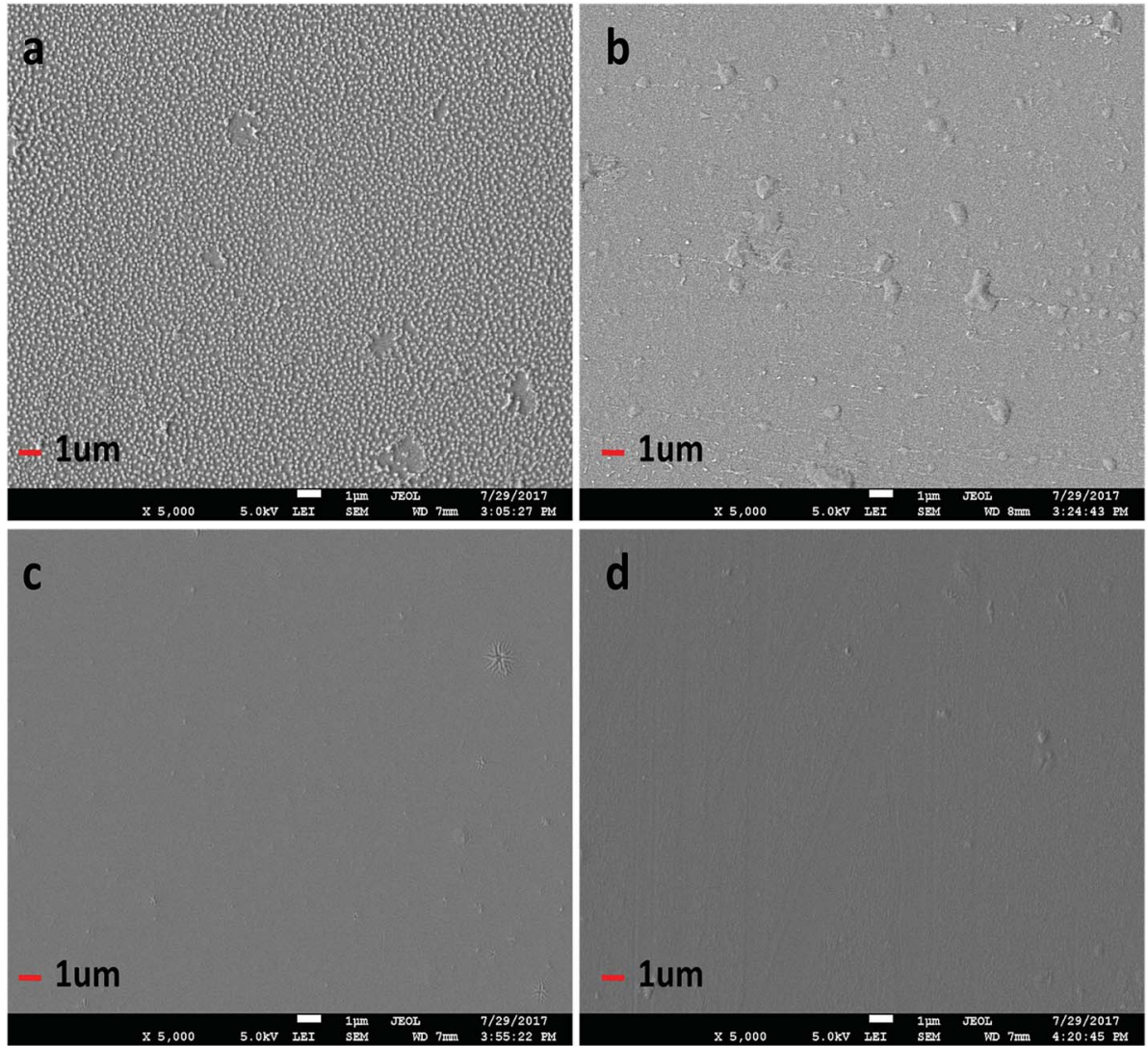

Fig. 7 SEM photographs of copolymers without POSS (a, b) and with POSS (c, d), (a) PCz-Ir1.0 (b) PCz-Ir2.5 (c) PCz-Ir2.5-POSS2 (d) PCz-Ir1.0POSS6. 
ternary copolymers PCz-Ir0.5-POSS2 $\sim$ PCz-Ir1.0-POSS8 were proximately close to those of binary copolymers PCz-Ir0.5 PCz-Ir5.0. It was showed that the content of POSS had no influence on the electrochemical properties of the polymers backbones, indicating that the presence of the POSS moieties in the copolymers does not result in changes in the electronic structure of the polymers, because POSS is inorganic nanoparticle and it has no conjugated structures. ${ }^{\mathbf{1 3 , 1 4 , 1 6}}$

\section{Thermal properties}

Thermal stability of the emissive materials is one of the most important aspects to improve device lifetime and reliability. It is well-known incorporation of POSS into materials can improve their thermal stability. Taking the binary copolymer PCz-Ir2.5 and ternary copolymer PCz-Ir2.5-POSS2 for example, from TGA curves of PCz-Ir2.5 and PCz-Ir2.5-POSS2 (Fig. 6), it was observed that the POSS loading did not change the polymer degradation path, and the thermal properties of ternary copolymer PCz-Ir2.5-POSS2 was similar to those of binary copolymer PCz-Ir2.5. The thermal decomposition temperatures $\left(T_{\mathrm{d}}, 5 \%\right.$ weight loss temperature) of ternary copolymer PCz-Ir2.5-POSS2 with POSS was $9{ }^{\circ} \mathrm{C}$ higher than that of binary copolymer PCz-Ir2.5 without POSS. It indicates that the grafted bulky POSS can enhance the thermal stability of the luminescent materials due to the presence of inorganic Si-O cage shielding effect, which limits the heat transfer and protects the organic part of polymer from the heat effect of attack. ${ }^{15,39}$

\section{SEM and SPM photographs}

Scanning electronic microscope (SEM) and scanning probe microscope (SPM) are used to investigate the effect of POSS on the surface morphology of the copolymer thin films. The SEM photographs and SPM 3D images of copolymer thin films without POSS and with POSS are shown in Fig. 7 and 8, respectively. From Fig. 7, it is found that the surface morphologies of copolymer films with POSS (PCz-Ir2.5-POSS2, PCz-Ir1.0-POSS6) are uniform and smooth, whereas the copolymers films without POSS (PCz-Ir1.0, PCz-Ir2.5) show rough surface with undissolved polymers particles. From the 3D images (Fig. 8), it is found that the ternary copolymer films (PCz-Ir2.5-POSS2, PCz-Ir1.0-POSS6) show a smooth surface with $R_{\mathrm{a}}$ values of $7.77 \mathrm{~nm}$ and $7.25 \mathrm{~nm}$, respectively, and the $R_{\mathrm{a}}$ values of binary polymers (PCz-Ir1.0, PCz-Ir2.5) are $11.8 \mathrm{~nm}$ and $37.8 \mathrm{~nm}$, respectively. These results imply the presence of the POSS groups can effectively enhance the polymers solubility and film-forming property.
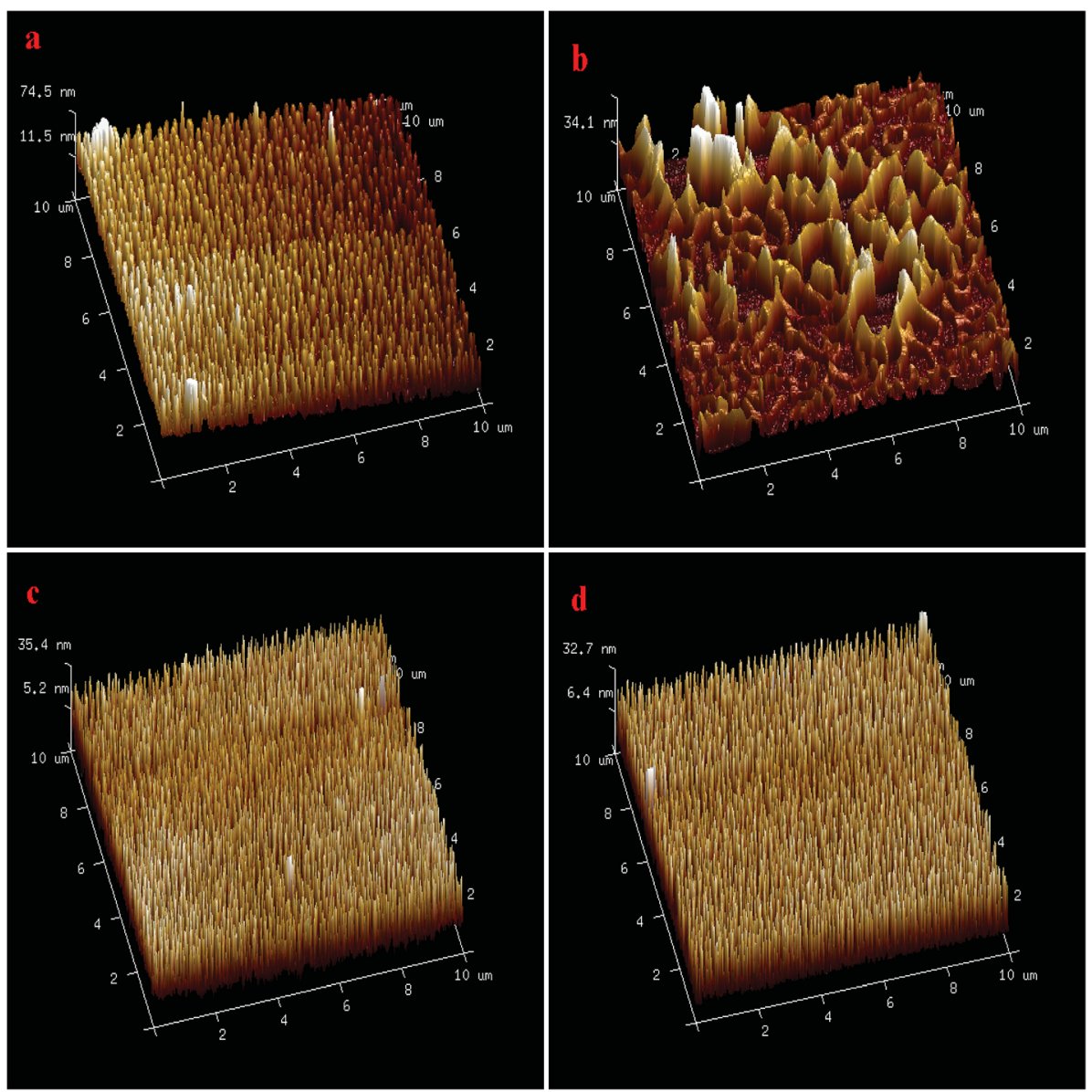

Fig. 8 SPM 3D-images of copolymers without POSS (a, b) and with POSS (c, d), (a) PCz-Ir1.0 (b) PCz-Ir2.5 (c) PCz-Ir2.5-POSS2 (d) PCz-Ir1.0POSS6. 


\section{Conclusion}

The non-conjugated copolymer hybrid materials containing the carrier-transporting carbazole units, iridium complex phosphorescence units and nano-scale particles POSS were prepared and studied. Compared to binary copolymers, the energy transfer from host to guest in the ternary copolymers is more efficient both in the solid state and in solution, and quantum efficiency $\left(\Phi_{\mathrm{pl}}=24.5-52.4 \%\right)$ of the ternary copolymers are much higher than those of the binary copolymers $\left(\Phi_{\mathrm{pl}}=7.0-\right.$ $24.2 \%$ ) in their solid state, which indicates that incorporation of the POSS as pendant group into the polymer backbone can promote the luminescence properties of the copolymers dramatically. The photoluminescence decays of all copolymers in solid state follow bi-exponential and their phosphorescence lifetimes are $0.28-1.60 \mu \mathrm{s}$. The ternary copolymers exhibit good solubility in common organic solvents, and better film formation property for the solution processing techniques. Besides, there is a practical prospect for the free radical copolymerization method which is convenient and easy to purify.

\section{Conflicts of interest}

There are no conflicts to declare.

\section{Acknowledgements}

This work was supported by the National Natural Science Foundation of China (21374017 and 21574021), Natural Science Foundation of Fujian Province (2017J01683), Program for Innovative Research Team in Science and Technology in Fujian Province University (IRTSTFJ).

\section{Notes and references}

1 F. Wang, X. H. Lu and C. B. He, J. Mater. Chem., 2011, 21, 2775-2782.

2 D. B. Cordes, P. D. Lickiss and F. Rataboul, Chem. Rev., 2010, 110, 2081-2173.

3 J. Huang, W. N. Wang, J. J. Gu, W. Z. Li, Q. H. Zhang, Y. Ding, K. Xi, Y. X. Zheng and X. D. Jia, Polymer, 2014, 55, 6696-6707.

4 D. Y. Kim, S. Kim, S. A. Lee, Y. E. Choi, W. J. Yoon, S. W. Kuo, C. H. Hsu, M. J. Huang, S. H. Lee and K. U. Jeong, J. Phys. Chem. C, 2014, 118, 6300-6306.

5 H. M. Lin, K. H. Hseih and F. C. Chang, Microelectron. Eng., 2008, 85, 1624-1628.

6 T. Seckin, S. Köytepe and H. I. Adıüzel, Mater. Chem. Phys., 2008, 112, 1040-1046.

7 Y. L. Liu and M. H. Fangchiang, J. Mater. Chem., 2009, 19, 3643-3647.

8 D. X. Wang, L. G. Li, W. Y. Yang, Y. J. Zuo, S. Y. Feng and H. Z. Liu, RSC Adv., 2014, 4, 59877-59884.

9 L. G. Li, S. Y. Feng and H. Z. Liu, RSC Adv., 2014, 4, 3913239139.

10 T. Hirai, M. Leolukman, C. C. Liu, E. Han, Y. J. Kim, Y. Ishida, T. Hayakawa, M. A. Kakimoto, P. F. Nealey and P. Gopalan, Adv. Mater., 2009, 21, 4334-4338.
11 C. H. Lu, S. W. Kuo, C. F. Huang and F. C. Chang, J. Phys. Chem. C, 2009, 113, 3517-3524.

12 S. W. Kuo and F. C. Chang, Prog. Polym. Sci., 2011, 36, 16491696.

13 T. F. Zhang, J. Z. Wang, M. X. Zhou, L. Ma, G. Z. Yin, G. X. Chen and Q. F. Li, Tetrahedron, 2014, 70, 2478-2486.

14 J. M. Kang, H. J. Cho, J. Lee, J. I. Lee, S. K. Lee, N. S. Cho, D. H. Hwang and H. K. Shim, Macromolecules, 2006, 39, 4999-5008.

15 V. Ervithayasuporn, J. Abe, X. Wang, T. Matsushima, H. Murata and Y. Kawakami, Tetrahedron, 2010, 66, 93489355.

16 J. Lee, H. J. Cho, B. J. Jung, N. S. Cho and H. K. Shim, Macromolecules, 2004, 37, 8523-8529.

17 C. H. Chou, S. L. Hsu, K. Dinakaran, M. Y. Chiu and K. H. Wei, Macromolecules, 2005, 38, 745-751.

18 S. Xiao, M. Nguyen, X. Gong, Y. Cao, H. B. Wu, D. Moses and A. J. Heeger, Adv. Funct. Mater., 2003, 13, 25-29.

19 H. J. Cho, D. H. Hwang, J. I. Lee, Y. K. Jung, J. H. Park, J. Lee, S. K. Lee and H. K. Shim, Chem. Mater., 2006, 18, 37803787.

20 J. D. Froehlich, R. Young, T. Nakamura, Y. Ohmori, S. Li, A. Mochizuki, M. Lauters and G. E. Jabbour, Chem. Mater., 2007, 19, 4991-4997.

21 W. J. Lin, W. C. Chen, W. C.Wu, Y. H. Niu and A. K.-Y. Jen, Macromolecules, 2004, 37, 2335-2341.

22 Y. L. Chu, C. C. Cheng, Y. P. Chen, Y. C. Yen and F. C. Chang, J. Mater. Chem., 2012, 22, 9285-9292.

23 X. H. Yang, J. D. Froehlich, H. S. Chae, S. Li, A. Mochizuki and G. E. Jabbour, Adv. Funct. Mater., 2009, 19, 2623-2629.

24 W. Y. Lai, J. W. Levell, P. L. Burn, S. C. Lo and I. D. W. Samuel, J. Mater. Chem., 2009, 19, 4952-4959.

25 K. B. Chen, Y. P. Chang, S. H. Yang and C. S. Hsu, Thin Solid Films, 2006, 514, 103-109.

26 D. M. Sun, Z. J. Ren, M. R. Bryce and S. K. Yan, J. Mater. Chem. C, 2015, 3, 9496-9508.

27 M. Singh, H. S. Chae, J. D. Froehlich, T. Kondou, S. Li, A. Mochizuki and G. E. Jabbour, Soft Matter, 2009, 5, 30023005.

28 X. H. Yang, J. D. Froehlich, H. S. Chae, B. T. Harding, S. Li, A. Mochizuki and G. E. Jabbour, Chem. Mater., 2010, 22, 4776-4782.

29 T. Z. Yu, Z. X. Xu, W. M. Su, Y. L. Zhao, H. Zhang and Y. J. Bao, Dalton Trans., 2016, 45, 13491-13502.

30 L. Deng, P. T. Furuta, S. Garon, J. Li, D. Kavulak, M. E. Thompson and J. M. J. Frechet, Chem. Mater., 2006, 18, 386-395.

31 M. J. Lin, D. D. Li, X. P. Wang, C. P. Luo and Q. D. Ling, J. Macromol. Sci., Part A: Pure Appl. Chem., 2016, 53, 222226.

32 M. Nonoyama, Bull. Chem. Soc. Jpn., 1974, 47, 767-768.

33 S. Lamansky, P. Djurovich, D. Murphy, F. Abdel-Razzaq, R. Kwong, I. Tsyba, M. Bortz, B. Mui, R. Bau and M. E. Thompson, Inorg. Chem., 2001, 40, 1704-1711.

34 J. D. Lichtenhan, Y. A. Otonari and M. J. Carr, Macromolecules, 1995, 28, 8435-8437. 
35 W. J. Wang, M. L. Chen, X. W. Chen and J. H. Wang, Chem. Eng. J., 2014, 242, 62-68.

36 S. F. Weng, Fourier Transform Infrared Spectral Analysis, Beijing, China, Chemical Industry Press, 2010, pp. 377388.

37 S. Lamansky, P. Djurovich, D. Murphy, F. Abdel-Razzaq, H.-E. Lee, C. Adachi, P. E. Burrows, S. R. Forrest and M. E. Thompson, J. Am. Chem. Soc., 2001, 123, 4304-4312.
38 J. S. Huang, T. Goh, X. K. Li, M. Y. Sfeir, E. A. Bielinski, S. Tomasulo, M. L. Lee, N. Hazari and A. D. Taylor, Nat. Photonics, 2013, 7, 479-485.

39 F. F. Du, H. Wang, Y. Y. Bao, B. Liu, H. T. Zheng and R. K. Bai, J. Mater. Chem., 2011, 21, 10859-10864. 